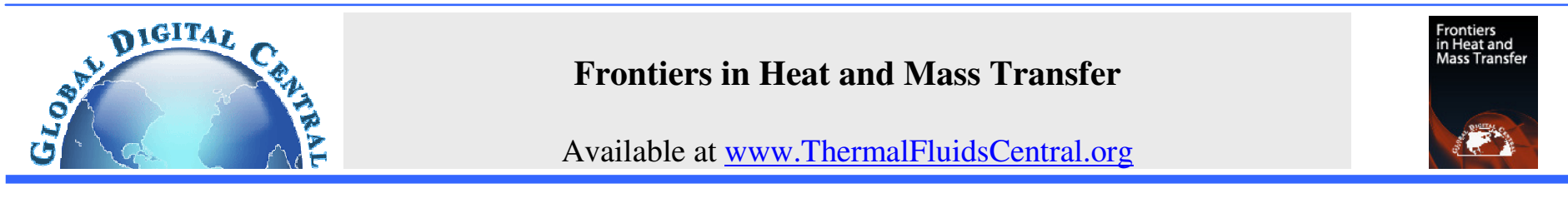

\title{
NUMERICAL ANALYSIS OF NATURAL CONVECTION IN A RIGHT- ANGLED TRIANGULAR ENCLOSURE
}

\author{
Manoj Kr. Triveni*, Dipak Sen, RajSekhar Panua
}

National Institute of Technology, Agartala, Tripura, 799055, India

\begin{abstract}
A numerical investigation has been performed for heat transfer analysis in a right-angled triangular enclosure filled with water. The side wall of the enclosure is maintained at high temperature compare to the base wall while hypotenuse is kept thermally insulated. Two - dimensional steady-state continuity, momentum and energy equations along with the boussinesq approximation are solved by finite volume method using commercial available software, FLUENT 6.3. The computational results are shown in terms of isotherms, streamlines and velocity contour for Rayleigh number $\left(10^{5} \leq \mathrm{Ra} \leq 10^{7}\right)$. The heat transfer is presented in terms of local and average Nusselt number. The result encapsulates that both flow field and temperature distributions are affected with Rayleigh number. The simulated results are validated with the experimental and numerical results and it shows a good agreement with the published results. Finally, a correlation for Nusselt number $(\mathrm{Nu})$ with Rayleigh number (Ra) has been developed for vertical hot wall.

Keywords: Natural convection, Triangular enclosure, Rayleigh number, Numerical simulation.
\end{abstract}

\section{INTRODUCTION}

Many researchers have been working on natural convection using a triangular cavity due to its wide applications in building insulation, solar collector and electronic equipments. Akinsete and Coleman (1982) were used a numerical technique to investigate the laminar natural convection in air contained in a long horizontal right-triangular enclosure. Steady-state solutions had been obtained for height-base ratios of $0.0625</ H / B \leqslant 1.0$ for Grashof number of $800 \leqslant G r_{(B)} \leqslant 64$ 000 . Results were reported that the heat transfer across the base wall increases towards the hypotenuse/base intersection such that the third of the base length nearest the intersection accounts for about $60 \%$ of the heat transferred across the base. Asan and Namli (2000) have carried out a numerical study for laminar natural convection in a pitched roof cross section under summer day boundary conditions. Problem was solved for different height - base ratio and $\mathrm{Ra}=10^{3}-10^{6}$. Aydin and Yesiloz (2011) have studied the buoyancy induced flow and heat transfer mechanisms in a water-filled quadrantal cavity experimentally and numerically. It has been concluded from the investigation that the influence of Rayleigh number is insignificant at $\mathrm{Ra}<10^{3}$ and it becomes significant beyond $10^{4}$.

Basak et al. (2012) have worked on entropy generation due to natural convection in right-angled triangular enclosures filled with porous media. It was observed that the total entropy generation is increasing function of Darcy number. Ghasemi and Aminossadati (2010) have done a numerical study on natural convection in right triangular enclosure with heat source on its vertical wall and water- $\mathrm{CuO}$ nanofluid as a source medium. Parameters such as Rayleigh number, solid volume fraction, heat source location and enclosure aspect ratio which affect the heat transfer rate were examined. Enhancement in heat transfer was observed for upper location of heat source and high aspect ratio for high Rayleigh number. Kaluri et al. (2010) have analyzed natural convection in right-angled triangular enclosures with various top angles. It was observed that for lower angle $\left(15^{\circ}\right)$, the average nusselt number remains invariant with increase in Ra, but the enhanced convection at higher Ra significantly affects the heat flow distribution. Kent (2009) has done a numerical analysis in an isosceles triangular cavity by varying the aspect ratio and base angle from $15^{\circ}$ to $17^{\circ}$. The lower aspect ratio has high heat transfer rate from the bottom surface of the triangular enclosure. Ridouane et al. (2005) have numerically computed laminar natural convection in a right-angled triangular cavity filled with air. The vertical side wall is considered as hot wall while cooling is done from hypotenuse of the triangular enclosure. It was examined that the heat transfer enhancement get decreased when both apex angle and Rayleigh number diminishes.

Saha (2011) has inspected the heat transfer and fluid flow in a triangular enclosure for instantaneous heating on the inclined walls. Investigation shows that the nusselt number was very high initially due to conduction effect and after that it decreases gradually and become steady state. Sun and Pop (2011) were numerically investigated the heat transfer behavior of nanofluids in a triangular enclosure filled with porous medium. Heat transfer rate was solved for different parameters such as Rayleigh number ( $\mathrm{Ra})$, size of heater $(\mathrm{Ht})$, position of heater (Yp) and enclosure aspect ratio. The maximum value of average Nusselt number is obtained for decreasing aspect ratio, lowering the heater position with the highest value of Rayleigh number and the largest size of heater. Also, heat transfer is enhancing with the increasing of solid volume fraction at low Rayleigh number. Tzeng et al. (2005) proposed the Numerical Simulation Aided Parametric Analysis method to solve natural convection equations in streamlinevorticity form.

Varol et al. (2006) used a flush mounted heater on side wall of the triangular cavity. Aspect ratio of the triangle, location of heater, length of heater and Rayleigh number are some parameters which considered for heat transfer analysis. It was reported that the heat transfer is

*Corresponding author. Email: triveni_mikky@yahoo.com 
affected due to both position and location of heater and increases with the increase in Rayleigh number. Varol et al. (2007) attached a thin solid adiabatic fin in porous right-angled triangular enclosure and solved numerically using finite volume method. They found that the Nusselt number is an increasing function of Rayleigh number and with the increasing of dimensionless solid adiabatic fin height, the heat transfer rate decreases. Varol et al. (2008) examined heat transfer and fluid flow in a triangular enclosure filled with fluid-saturated porous medium with a conducting thin fin on the hot vertical wall. The investigation explored that the increasing value of $\mathrm{Y}_{\mathrm{p}}$ and $\mathrm{W}_{\mathrm{p}}$ leads to decrease in heat transfer. Natural convective flow and heat transfer in an inclined quadrantal cavity is studied experimentally and numerically by Yesiloz and Aydin (2011). The effects of the inclination angle, $\varphi$ and the Rayleigh number, $\mathrm{Ra}$ on fluid flow and heat transfer are investigated for the range of angle of inclination between $0^{\circ} \leq \varphi \leq 360^{\circ}$, and $\mathrm{Ra}$ from $10^{5}$ to $10^{7}$. It was revealed that heat transfer changes dramatically according to the inclination angle which affects convection currents inside, i.e. flow physics inside. Yesiloz and Aydin (2013) have investigated natural convection heat transfer experimentally and numerically in a right-angled triangular cavity. The cavity is heated from below and cooled from the side wall. A new approach is used to overcome the singularity effect. From the result, it is observed that the heat transfer rate increases with Rayleigh number and a correlation has been developed for $\mathrm{Nu}$.

From the above literature assessment, it is noticed that the plenty of work has been done on a right-angle triangular cavity considering vertical wall as hot wall. Different heat transport medium such as air, water and nanofluid used as working medium for heat transport but no correlation has been developed for vertical wall to understand the phenomena of heat transfer. Hence a correlation is developed between average Nusselt number and Rayleigh number for vertical hot wall of triangular enclosure filled with water.

\section{PROBLEM DESCRIPTION}

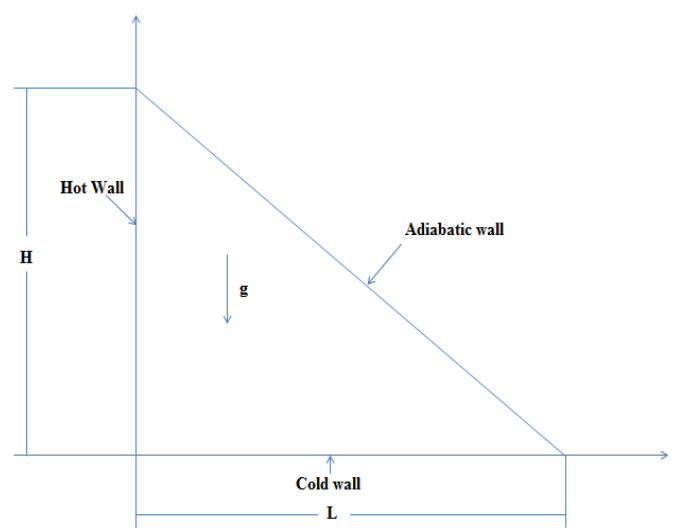

Fig. 1 Graphical presentation of triangular cavity.

The schematic diagram of the triangular enclosure is shown in figure 1 . Copper is used for hot and cold walls while Plexiglas as an insulating material for inclined wall. Side and base walls of the triangular cavity are thermally active and the temperature of the side wall is higher than the base wall $\left(\mathrm{T}_{\mathrm{h}}>\mathrm{T}_{\mathrm{c}}\right)$ while the hypotenuse is considered as an adiabatic wall.

\subsection{Mathematical Formulation}

The governing equations are obtained on certain assumptions such as:

- All walls are assumed to be impermeable.

- Radiation effect is negligible.

- Fluid is considered as steady and laminar.

- All properties of the fluid are presumed to be constant except density which changes with temperature (Boussinesq approximation).
With these assumptions the dimensional governing equations can be written as:

$$
\begin{aligned}
& \frac{\partial u}{\partial x}+\frac{\partial v}{\partial y}=0 \\
& u \frac{\partial u}{\partial x}+v \frac{\partial u}{\partial y}=-\frac{1}{\rho} \frac{\partial p}{\partial x}+v\left(\frac{\partial^{2} u}{\partial x^{2}}+\frac{\partial^{2} u}{\partial y^{2}}\right) \\
& u \frac{\partial v}{\partial x}+v \frac{\partial v}{\partial y}=-\frac{1}{\rho} \frac{\partial p}{\partial y}+v\left(\frac{\partial^{2} v}{\partial x^{2}}+\frac{\partial^{2} v}{\partial y^{2}}\right)+g \beta\left(T-T_{0}\right) \\
& u \frac{\partial T}{\partial x}+v \frac{\partial T}{\partial y}=\alpha\left(\frac{\partial^{2} T}{\partial x^{2}}+\frac{\partial^{2} T}{\partial y^{2}}\right)
\end{aligned}
$$

By using dimensionless parameters such as

$$
\begin{aligned}
& X=\frac{x}{H}, Y=\frac{y}{H}, U=\frac{u H}{\alpha}, V=\frac{v H}{\alpha}, \theta=\frac{T-T_{c}}{T_{h}-T_{c}}, \\
& P=\frac{p H^{2}}{\rho \alpha^{2}}, \operatorname{Pr}=\frac{v}{\alpha}, R a=\frac{g \beta\left(T_{h}-T_{c}\right) H^{3}}{\alpha v}
\end{aligned}
$$

The dimensionless governing equation can be written as $\frac{\partial U}{\partial X}+\frac{\partial V}{\partial Y}=0$

$U \frac{\partial U}{\partial X}+V \frac{\partial U}{\partial Y}=-\frac{\partial P}{\partial X}+\operatorname{Pr}\left(\frac{\partial^{2} U}{\partial X^{2}}+\frac{\partial^{2} U}{\partial Y^{2}}\right)$

$U \frac{\partial V}{\partial X}+V \frac{\partial V}{\partial Y}=-\frac{\partial P}{\partial Y}+\operatorname{Pr}\left(\frac{\partial^{2} V}{\partial X^{2}}+\frac{\partial^{2} V}{\partial Y^{2}}\right)+R a \operatorname{Pr} \theta$

$U \frac{\partial \theta}{\partial X}+V \frac{\partial \theta}{\partial Y}=\left(\frac{\partial^{2} \theta}{\partial X^{2}}+\frac{\partial^{2} \theta}{\partial Y^{2}}\right)$

And dimensionless boundary conditions are:

at the hot wall: $\theta=1, \mathrm{U}=\mathrm{V}=0$ at $\mathrm{X}=0$ and $0<\mathrm{Y}<1$

at the cold wall: $\theta=0, \mathrm{U}=\mathrm{V}=0$ at $\mathrm{Y}=0$ and $0<\mathrm{X}<1$

at the adiabatic wall: $\partial \theta / \partial \mathrm{n}=0, \mathrm{U}=\mathrm{V}=0$ at $0<\mathrm{X}<1$ and $0<\mathrm{Y}<1$

\subsection{Numerical Analysis}

The problem has solved by commercial available software; FLUENT 6.3 which hire finite volume method. For fluid based problem, FVM is providing better flexibility and preciseness. SIMPLE algorithm coupled with pressure and velocity is used to solve the dimensionless governing equations (6-9) with the corresponding boundary conditions (10). Momentum and energy equations are discretized by second order upwind technique while the pressure interpolation is done by PRESTO scheme. The local nusselt number is calculated with standard nusselt number definition $\left(\mathrm{Nu}_{x}=\mathrm{h} . \mathrm{L} / k\right)$ and the average Nusselt number defined by Yesiloz and Aydin (2013) for triangular cavity is:

$N u=\left.\frac{d T}{d \phi}\right|_{\phi=0} \frac{1}{T_{h}-T_{c}} \frac{\Pi}{2}$

The stream function can defined as

$u=\frac{\partial \psi}{\partial x}, v=-\frac{\partial \psi}{\partial x}$ 
And the non-dimensional stream function calculate by

$\Psi=\psi / \alpha$

\section{PROBLEM VALIDATION}

\subsection{Grid Independency Test}

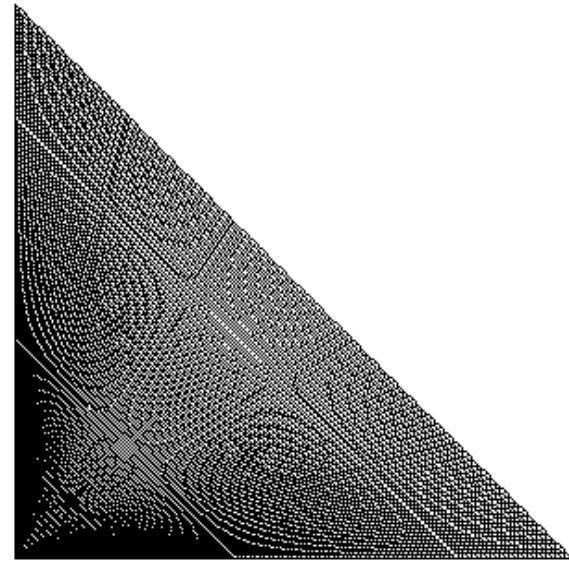

Fig. 2 Grid structure for physical domain.
The local Nusselt number and stream functions have calculated for the triangular cavity by creating meshes but the size and structure of the grid or mesh should be appropriate according the cavity for highly accurate results. Hence, grid independency test is conducted for different sizes such as $1600,3600,6400,10000,14400$ and 19600 to examine the suitable grid density and recommended grid is shown in figure 2 .

Table1 Relative error analysis with different grid sizes.

\begin{tabular}{|c|c|c|c|c|}
\hline Cells & $\boldsymbol{\Psi}_{\max }$ & $\begin{array}{c}\text { Deviati } \\
\text { on (\%) }\end{array}$ & Nu & $\begin{array}{c}\text { Deviatio } \\
\text { n (\%) }\end{array}$ \\
\hline 3600 & 3.3623 & & 5.63 & \\
\hline 6400 & 3.4482 & 2.49 & 5.99 & 6.075 \\
\hline 10000 & 3.5261 & 2.21 & 6.25 & 4.089 \\
\hline 14400 & 3.4163 & 3.12 & 6.40 & 2.400 \\
\hline 19600 & 3.3547 & 1.8 & 6.38 & 0.417 \\
\hline 25600 & 3.5613 & 5.8 & 6.68 & 4.500 \\
\hline
\end{tabular}

The independency on grid is considered on the basis of less deviation in non-dimensional stream function and Nusselt number which calculated by relative error analysis. Table 1 explicates the less deviation at grid 14400 and 19600 compare to others. Hence, 14400 grids have recommended to the present work for less conservation time.

\subsection{Validation of Results}
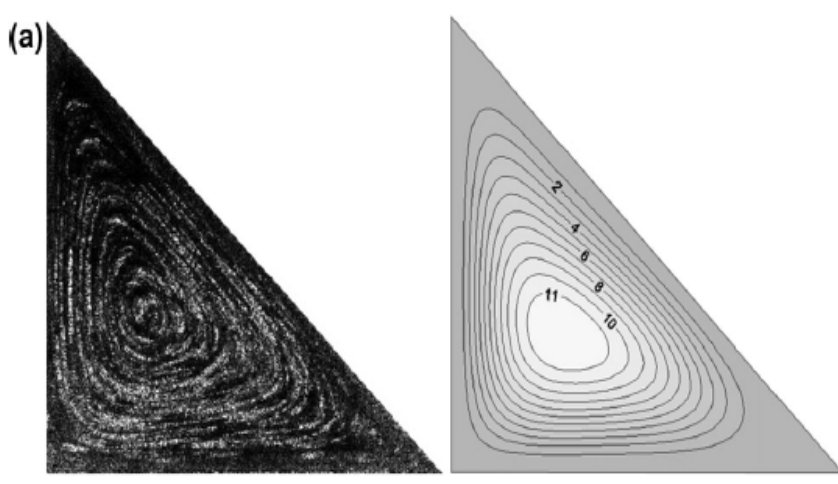

$\Psi_{\max }=12.12$

$\Psi_{\min }=0$
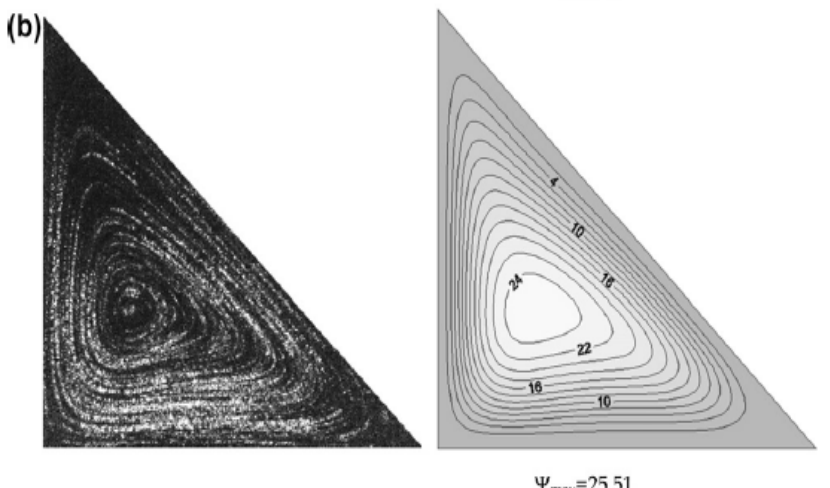

$\Psi_{\min }=0$

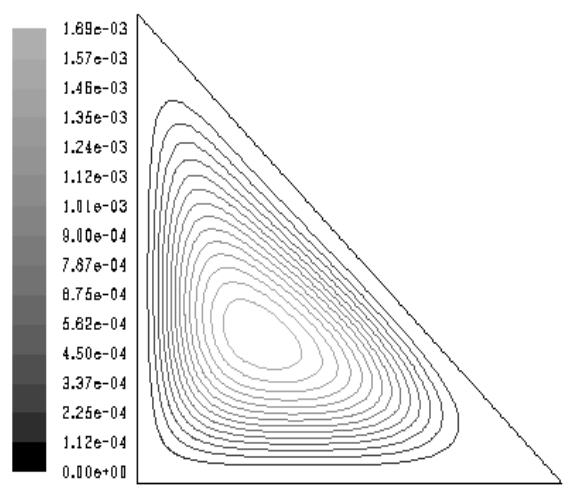

$\Psi_{\max }=12.09$

$\Psi_{\min }=0$

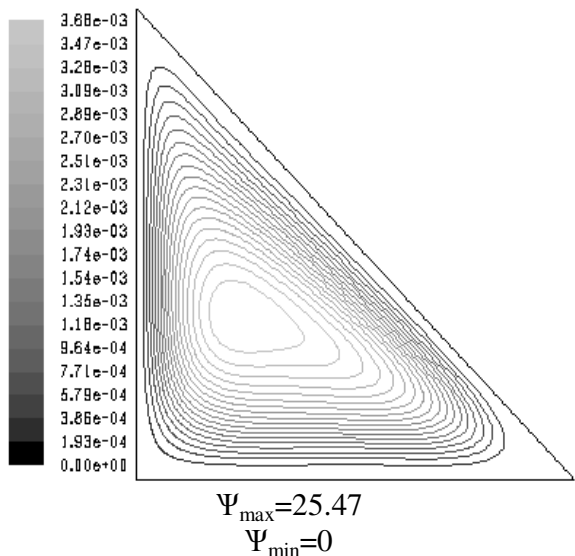

Fig. 3 Experimental and Numerical streamlines (left and middle) from Yesiloz and Aydin (2013) and numerical simulation (right) from the present study for a) $\mathrm{Ra}=10^{5}$ and $\mathrm{b}$ ) $\mathrm{Ra}=5 \times 10^{5}$. 
(a)
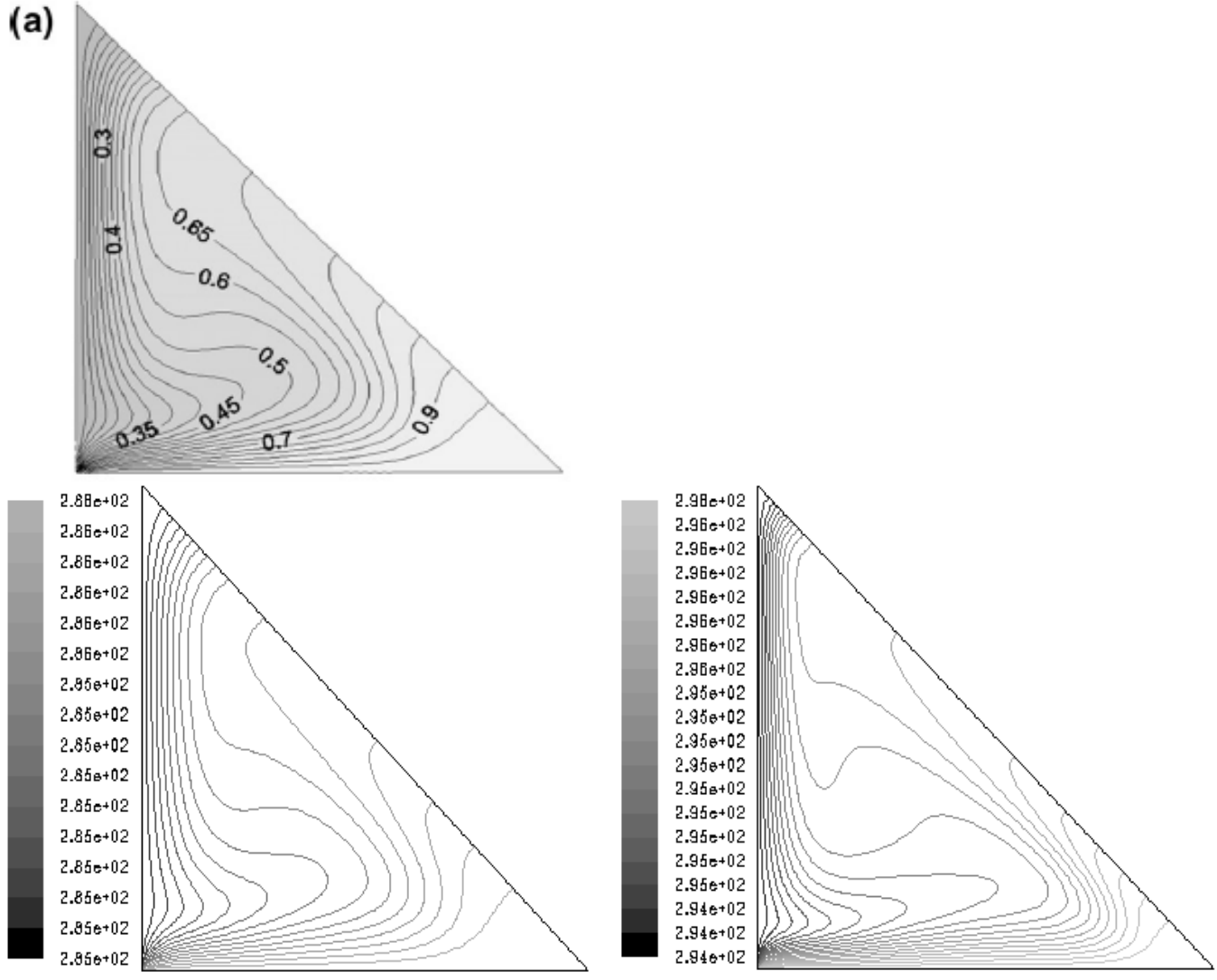

Fig. 4 Experimental and Numerical isotherms (above) from Yesiloz and Aydin (2013) and numerical isotherms (below) from the present study for a) $\mathrm{Ra}=10^{5}$ and b) $\mathrm{Ra}=5 \times 10^{5}$.

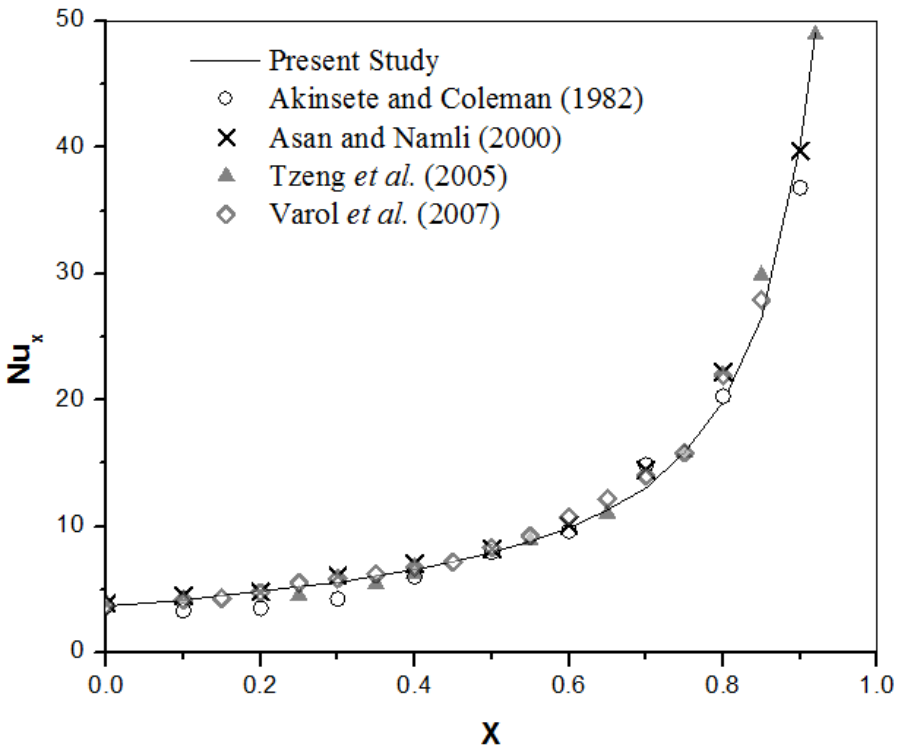

Fig. 5 Validation of present work with other published data for a triangular cavity filled with air at $\operatorname{Ra}=2772, \operatorname{Pr}=0.73$.

The numerical investigation of laminar natural convection in a triangular cavity has done for different Rayleigh number. The obtained results have been validated with the existing results for right-angle triangular enclosure filled with water when the bottom wall is heated and cooling is done from the side wall. The results obtained at $\mathrm{Ra}=10^{5}$ and $\mathrm{Ra}=5 \times 10^{5}$ are validated in terms of streamlines and isotherms with the existing experimental and numerical outcomes of Yesiloz and Aydin (2013) keeping same boundary conditions which is shown in figure 3 and 4 respectively. Also, variation in local Nusselt number with position for triangular cavity is validated with the published data which displayed in Fig. 5. Both results are showing quite good agreement with the published results.

\section{RESULTS AND DISCUSSIONS}

The present problem intended to investigate the heat transfer for different Rayleigh number $\left(10^{5}\right.$ to $\left.10^{7}\right)$ in a triangular cavity. The results have shown by streamlines, isotherms and velocity contour.

Fig. 6 and 7 shows the effect of Rayleigh number on flow field, temperature and velocity distribution. Results unfold that the heat transfer is mainly depending on the fluid flow and temperature distributions. At low Rayleigh number, figure 6a, streamline is nearly circular at the center and are far from the hot wall. As the Rayleigh number increases, streamlines are getting denser at the lower portion of the hot wall. It is no longer circular at the center and turns into a peculiar shape which can be shown in fig. 6 (b) - (e). The outer rings of the streamlines become curvilinear, grow into jet like shape and getting closure to the right corner of the triangular cavity. It is noticeable that the vortex flow of the fluid is cumulative with higher Rayleigh number which indicates the rate of heat transfer is enhancing between hot wall and fluid with increasing Ra. 
a)

b)

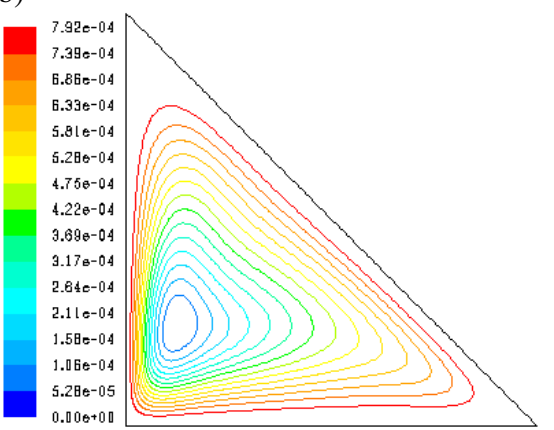

c)

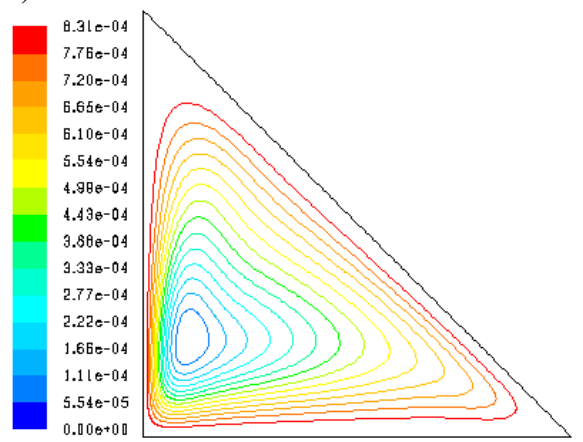

d)

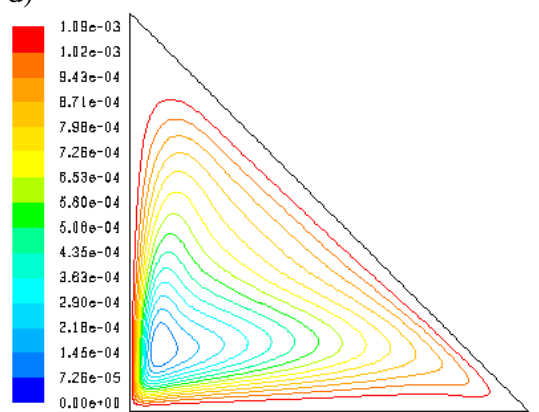

e)

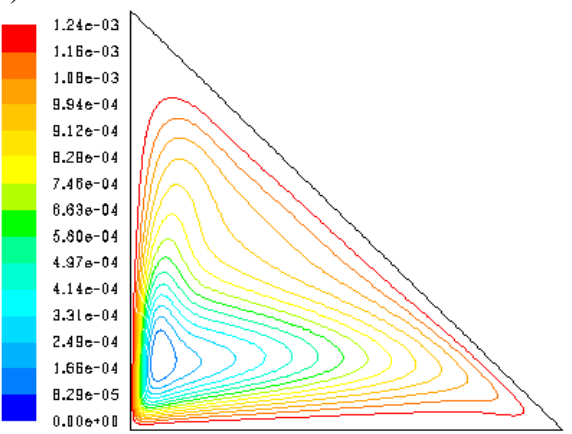

Isotherms
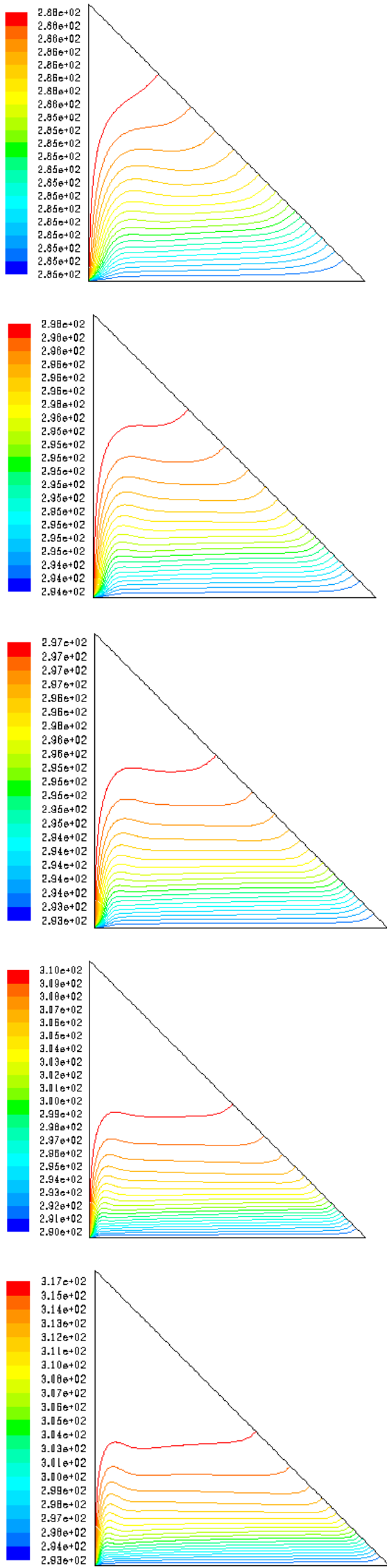

Fig. 6 Streamline (left column) and Isotherms (right column) for; a) $\mathrm{Ra}=10^{5}$, b) $\mathrm{Ra}=5 \times 10^{5}$, c) $\mathrm{Ra}=10^{6}$, d) $\mathrm{Ra}=5 \times 10^{6}$, e) $\mathrm{Ra}=10^{7}$. 
The right column of the figure 6 presented the distribution of the isotherms inside the cavity. At $\mathrm{Ra}=10^{5}$, isotherms are distributed over the entire cavity. At higher Rayleigh number $\left(\mathrm{Ra}=5 \times 10^{6}\right.$ and $\left.\mathrm{Ra}=10^{7}\right)$ isotherms are separated from the upper corner and getting crowded towards the cold wall and boundary layer formation occurs near the cold wall. It is happening because density of the fluid come to be lighter with growing temperature difference which transfer heat to the cold wall carried by the fluid from the hot wall and thus enhancing the heat transfer rate.

\section{Velocity contours}

a)

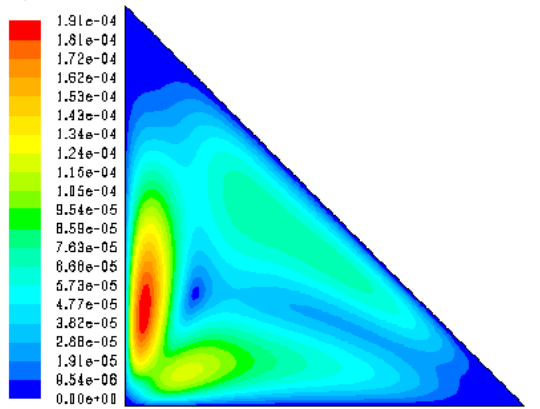

c)

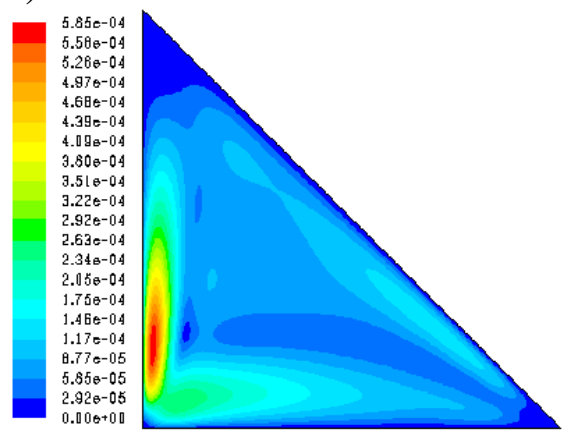

e)

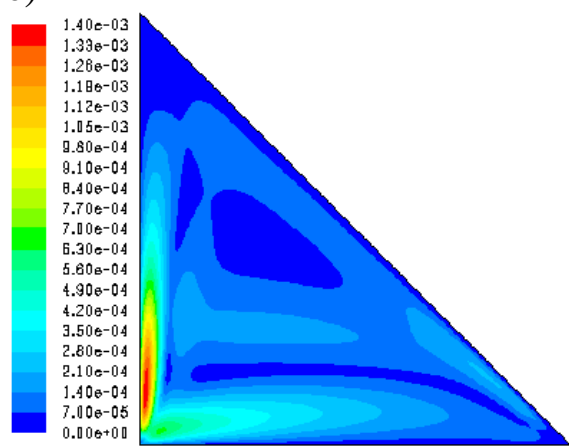

b)

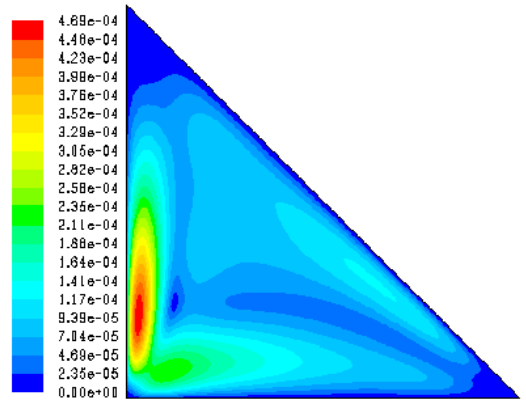

d)

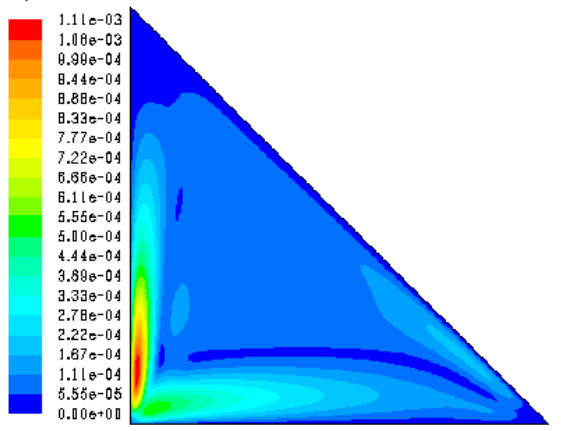

Fig. 7 Velocity contour for Rayleigh number; a) $R a=10^{5}$, b) $R a=5 \times 10^{5}$, c) $10^{6}$, d) $5 \times 10^{6}$, e) $\mathrm{Ra}=10^{7}$.

Figure 7 presents the velocity contour in triangular cavity for variable Rayleigh number. The heat transfer at the corner of the triangular caity is due to conduction because of negligilbe fluid movment. There are two rings present in velocity contour digram for Ra $=10^{5}$ which shown in figure $7 \mathrm{a}$. However, at high Rayleigh number the vertical ring become thinner and thinner as well as the lower ring is vanishing. From Fig. 6 and 7, it is apparent that density and viscocity of the fluid are decreasing with the increment of fluid velocity and is resonsible for enrichment of convective heat transfer at high rayleigh number. The enhancement in convection attenuates the thermal boundary layer of the fluid will be responsible for heat transfer augmentation.

Figure 8 describes the heat transfer in terms of local Nusselt number $\left(\mathrm{Nu}_{\mathrm{x}}\right)$ for the hot wall. The $\mathrm{Nu}_{x}$ is almost equal to 0.5 near the hot wall for all $\mathrm{Ra}$. It is higher for non-dimensional position between 0 to 0.2 and after that $\mathrm{Nu}_{\mathrm{x}}$ is gradully decreasing with the increase of dimensionless postion in y-direction.

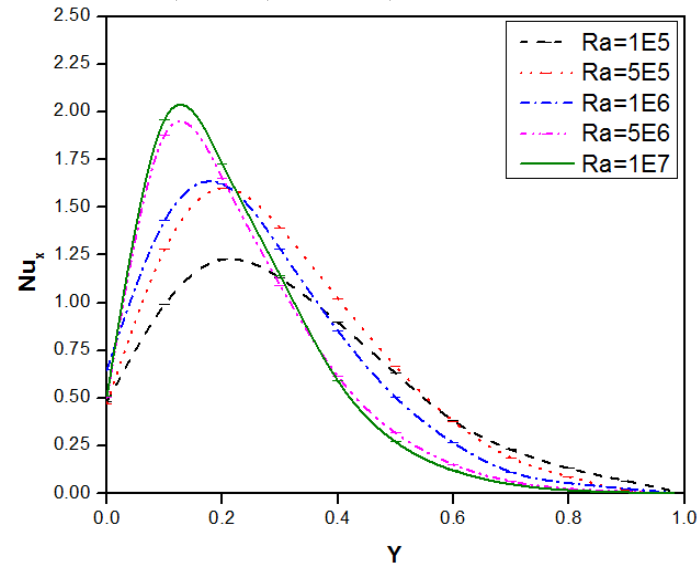

Fig. 8 Variation of local Nusselt number along hot wall for different Ra. 
Based on the numerical results obtained, a correlation equation can be established the dependence of $\mathrm{Nu}$ on $\mathrm{Ra}$ as follows:

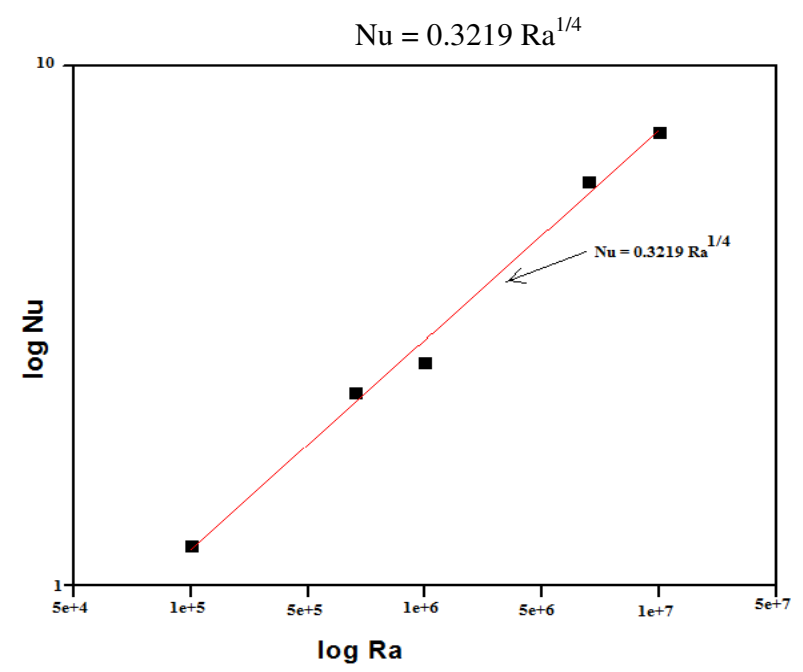

Fig. 9 Correlation curve of average $\mathrm{Nu}$ with $\mathrm{Ra}$.

\section{CONCLUSIONS}

A numerical analysis is done in a water filled right-angle triangular enclosure for different $\mathrm{Ra}$. The results are shown by streamline, isotherms and velocity contour. The heat transfer rate has shown in terms of local and average nusselt number. From the analysis it is observed that the average Nusselt number increases with the increase of Rayleigh number. The local Nusselt number is gradually decreasing with increasing non-dimensional parameter. Also, a correlation has been developed between Nusselt number and Rayleigh number for right-angled triangular cavity with vertical hot wall.

\section{NOMENCLATURE}

$g \quad$ acceleration due to gravity $\left(\mathrm{m} / \mathrm{s}^{2}\right)$

\section{$k \quad$ thermal conductivity $(\mathrm{W} / \mathrm{m} \cdot \mathrm{K})$}

$\mathrm{H} \quad$ height of the triangular cavity (m)

$\mathrm{L} \quad$ width of the triangular cavity $(\mathrm{m})$

$\mathrm{p} \quad$ pressure $(\mathrm{Pa})$

$\mathrm{P} \quad$ dimensionless pressure

$\mathrm{u}, \mathrm{v} \quad$ velocity component in $\mathrm{x}$ and $\mathrm{y}$ direction $(\mathrm{m} / \mathrm{s})$

$\mathrm{U}, \mathrm{V}$ dimensionless velocity component in $\mathrm{x}$ and $\mathrm{y}$ dirction

$\mathrm{T} \quad$ temperature $(\mathrm{K})$

$\mathrm{T}_{h} \quad$ hot wall temperature

$\mathrm{T}_{c} \quad$ cold wall temperature

Pr prandtl number

$\mathrm{Ra} \quad$ rayleigh number

$\mathrm{Nu}_{x} \quad$ local Nusselt number

$\mathrm{Nu} \quad$ average Nusselt number

\section{Greek Symbols}

$\begin{array}{ll}\alpha & \text { thermal diffusivity }\left(\mathrm{m}^{2} / \mathrm{s}\right) \\ \beta & \text { thermal expansion coefficient }(1 / \mathrm{K}) \\ \theta & \text { dimensionless temperature } \\ \rho & \text { density of water }(\mathrm{kg} / \mathrm{m} 3) \\ \mu & \text { dynamic viscosity of water }\left(\mathrm{kg} \cdot \mathrm{m} / \mathrm{s}^{2}\right) \\ v & \text { kinematic viscosity }\left(\mathrm{m}^{2} / \mathrm{s}\right) \\ \psi & \text { stream function }(1 / \mathrm{s}) \\ \Psi & \text { dimensionless stream function }\end{array}$

\section{Subscripts}

$h \quad$ hot wall

c cold wall

\section{ACKNOWLADGEMENT}

The authors wish to express their very sincerely thanks to the reviewers for their valuable comments and suggestions.

\section{REFERENCES}

Akinsete, V.A. and Coleman, T.A., 1982, "Heat Transfer by Steady Laminar Free Convection in Triangular Enclosures," International Journal of Heat and Mass Transfer, 25 (7), 991 - 998. http://dx.doi.org/10.1016/0017-9310(82)90074-6

Asan, H. and Namli, L., 2000, "Laminar Natural Convection in a Pitched Roof of Triangular Cross-Section: Summer Day Boundary Conditions," Energy and Buildings, 33 (1), 69 - 73. http://dx.doi.org/10.1016/S0378-7788(00)00066-9

Aydin, O. and Yesiloz, G., 2011, "Natural Convection in a Quadrantal Cavity Heated and Cooled on Adjacent Walls," ASME Journal of Heat Transfer, 133, 0525011-7. http://dx.doi.org/10.1115/1.4003044

Basak, T., Gunda, P. and Anandalakshmi, R., 2012, “Analysis of Entropy Generation during Natural Convection in Porous Right-angled Triangular Cavities with Various Thermal Boundary Conditions," Int. J. of Heat and Mass Transfer, 55, 4521-4535. http://dx.doi.org/10.1016/j.ijheatmasstransfer.2012.03.061

Ghasemi, B. and Aminossadati, S.M., 2010, "Brownian Motion of Nanoparticles in a Triangular Enclosure with Natural Convection," Int. Journal of Thermal Science, 49, 931-940. http://dx.doi.org/10.1016/j.ijthermalsci.2009.12.017

Kaluri, R.S., Anandalakshmi, R. and Basak T., 2010, "Benjan's Heatline Analysis of Natural Convection in Right-angled Triangular Enclosure: Effects of Aspect-Ratio and Thermal Boundary Conditions," Int. J. of Thermal Sciences, 49, 1576-1592. http://dx.doi.org/10.1016/j.ijthermalsci.2010.04.022

Kent, E.F., 2009, “Numerical Analysis of Laminar Natural Convection in Isosceles Triangular Enclosures for Cold Base and Hot Inclined Walls," Mechanics Research Communication, 36, 497-508. http://dx.doi.org/10.1016/j.mechrescom.2008.11.002

Ridouane, E.I., Campo, A. and Chang, J. Y., 2005, "Natural Convection Patterns in Right-angled Triangular Cavities with Heated Vertical Sides and Cooled Hypotenuses," Journal of Heat Transfer, 127, 1181- 1186. http://dx.doi.org/10.1115/1.2033903

Saha, S. C., 2011, "Unsteady Natural Convection in a Triangular Enclosure under Isothermal Heating," Energy and Buildings, 43, 695703.

http://dx.doi.org/10.1016/j.enbuild.2010.11.014

Sun, Q. and Pop, I., 2011, "Free Convection In A Triangle Cavity Filled With A Porous Medium Saturated With Nanofluids With Flush Mounted Heater On The Wall," Int. Journal of Thermal Science, 50, 2141-2153.

http://dx.doi.org/10.1016/j.ijthermalsci.2011.06.005

Tzeng, S.C., Liou, J.H. and Jou, R.Y., 2005, "Numerical Simulationaided Parametric Analysis of Natural Convection in a Roof of Triangular Enclosures," Heat Transfer Engineering, 26, 69 - 79. http://dx.doi.org/10.1080/01457630591003899

Varol, Y., 2006, "Natural Convection in A Triangle Enclosure with Flush Mounted Heater on the Wall," Int. Communication in Heat and Mass Transfer, 33, 951-958.

http://dx.doi.org/10.1016/j.icheatmasstransfer.2006.05.003 
Varol, Y., Oztop, H.F. and Yilmaz, T., 2007, "Natural Convection in Triangular Enclosures with Protruding Isothermal Heater," Int. J. Heat Mass Transfer, 50, 2451-2462.

http://dx.doi.org/10.1016/j.ijheatmasstransfer.2006.12.027

Varol, Y., 2008, "Natural Convection in Porous Media-filled Triangular Enclosure with a Conducting Thin Fin on the Hot Vertical Wall," Proceedings of the Institution of Mechanical Engineers, Part C: Journal of Mechanical Engineering Science, 222(9), 1735-1743. http://dx.doi.org/10.1243/09544062JMES1031
Yesiloz. G. and Aydin, O., 2011, "Natural Convection in an Inclined Quadrantal Cavity Heated and Cooled on Adjacent Walls", Experimental Thermal and Fluid Science, 35, 1169-1176. http://dx.doi.org/10.1016/j.expthermflusci.2011.04.002

Yesiloz, G. and Aydin, O., 2013, "Laminar Natural Convection in Right-angled Triangular Enclosures Heated and Cooled on Adjacent Walls," Int. J. of Heat and Mass Transfer, 60, 365-374. http://dx.doi.org/10.1016/j.ijheatmasstransfer.2013.01.009
Yesiloz. G. and Aydin, O., 2011, "Natural Convection in an Inclined Quadrantal Cavity Heated and Cooled on Adjacent Walls," Experimental Thermal and Fluid Science, 35, 1169-1176. 